\title{
O TRADUTOR COMO TESTEMUNHA
}

\author{
Anna Basevi ${ }^{1}$ \\ 1Universidade Estadual do Rio de Janeiro, Rio de Janeiro \\ Rio de Janeiro, Brasil
}

\begin{abstract}
Resumo: A narrativa testemunhal convoca o leitor de maneira peculiar, pois sua responsabilidade de escuta (Jeanne Marie Gagnebin) o obriga a se posicionar, através de uma leitura profunda, dentro de uma witnesscommunity (Lina Insana) que garante a transmissão da narração. E como o leitor, o tradutor. Levando em conta aspectos narrativos e estilísticos da literatura testemunhal, é possível traçar uma proposta que visa enriquecer a ética e a prática de sua tradução identificando no ouvinte/leitor/tradutor uma testemunha. Ao mesmo tempo, são lançados interrogativos úteis à tradução em geral, aqui considerada, seguindo Henri Meschonnic, como relação entre dois textos. A reflexão é conduzida a partir da análise de problemáticas e cenas de tradução na obra Se questo è un uomo de Primo Levi, sobrevivente de Auschwitz e hoje considerado um grande escritor do século XX.
\end{abstract}

Palavras-chave: Literatura; Primo Levi; Testemunho; Tradução

\section{THE TRANSLATOR AS A WITNESS}

\begin{abstract}
The testimony literature involves the reader in a peculiar way, because his responsibility of listening (Jeanne Marie Gagnebin) forces him to position himself, through a deep reading, within a witness-community (Lina Insana) that guarantees the transmission of the narration. As the reader, the translator too. Taking into account narrative and stylistic aspects of the testimonial literature, it is possible to draw up a proposal that enriches the ethics and practice of its translation by identifying the listener / reader / translator as a witness. At the same time, useful interrogatives are sent to the translation in general, considered here, following Henri Meschonnic, as a relation between two texts. The reflection is conducted
\end{abstract}


from the analysis of translation problems and representation in Se questo è un uomo, the first book of Primo Levi, an Auschwitz survivor and great writer of the twentieth century.

Keywords: Literature; Primo Levi; Testimony; Translation

\section{As tarefas da testemunha}

Transmitir a experiência do campo de extermínio nazista a quem não a vivenciou pode se revelar uma empreitada comunicativa complexa, como sempre reiteraram as testemunhas e como o escritor italiano Primo Levi, sobrevivente de Auschwitz, expressa com estas linhas: "Pela primeira vez, então, nos damos conta de que a nossa língua não tem palavras para expressar esta ofensa: a aniquilação de um homem" (LEVI, 1988, p. 25). Robert Antelme, autor de L'espèce humaine, relata que, com a liberação do campo de Buchenwald, os soldados do exército anglo-americano depararam-se com prisioneiros impacientes de contar, e alguns, no começo, mostraram-se receptivos. Todavia,

em seguida os camaradas não param mais: contam, contam, contam, e logo o soldado não os ouve mais.[...] É que a ignorância do soldado aparece imensa.[...] Diante do soldado percebe-se já [...] a sensação de estar possuído por uma espécie de conhecimento infinito, impossível de ser transmitido. (ANTELME, 2010, p. 317, trad.nossa)

Apesar de as histórias dos deportados serem verdadeiras, Antelme conclui: "é preciso muito artifício para conseguir transmitir uma porção de verdade" (Ibidem). Não se trata apenas do repetido tema do "indizível", mas do que Semprun (1994, p. 25) chama de "invivível" e de como a literatura pode oferecer soluções de representação.

Em Ardous tasks. Primo Levi, translation and the transmission of holocaust testimony, Lina Insana lembra que diante da intenção 
dos nazistas de destruir as provas de seus crimes, surge o problema de como garantir a sobrevivência do testemunho, trasformando-o de ocultado em dito ou escrito. Tal transmissão pós-catástrofe, portanto, seria um ato de traslatio, meditado durante o período do campo, como preparação para o depois. O que seria confirmado por Levi (1997, I, p. 201) quando lembra a vontade "de sobreviver com a finalidade precisa de contar as coisas que tínhamos visto e suportado" ". Neste sentido, para Insana a testemunha é já um tradutor e a dificuldade de transmissão pode coincidir com a dificuldade de tradução, duas árduas tarefas.

A proposta da junção testemunho-tradução (INSANA, 2009, p. 4) consiste em mostrar o quanto a metáfora da tradução seria particularmente apropriada para o estudo da obra de Levi, não apenas por causa do trabalho realizado como tradutor, mas pela atenção dedicada às questões de linguagem, códigos, sistemas de escrita, e através da própria representação narrativa de cenas de tradução. Sabemos que em Se questo è un uomo a tradução das ordens em alemão torna-se logo forma de sobrevivência de grupos minoritários como os italianos, rodeados pelo alemão, o polonês, o ídiche. A língua alemã é necessária tanto quanto um complexo know-how de comunicação e de truques, a fim de saber exatamente onde ir, a quem pedir, o que dizer, o que não dizer. A percepção estranhante da Babel é trasmitida ao leitor através das inúmeras expressões, palavras ou frases estrangeiras (alemão, ídiche, tcheco, francês, polonês, húngaro) como a sequência para a palavra pão Brot-Broit-chleb-pain-lechem-kenyér, ou a palavra tijolo Ziegel-briques-tegula-cegli-kamenny-tégla. Pois dentro do Lager as diferenças linguísticas constituíam o marco divisório principal (MENGALDO, 2007, p. 85).

\footnotetext{
${ }^{1}$ Trad.nossa. Trata-se da "Appendice" a Se questo è un uomo, acrescentada pelo escritor à edição escolar de 1976.
} 


\section{Deslizamentos da tradução}

Embora o escritor nos informa que no Lager de Mauthausen, ainda mais diversificado linguisticamente do que Auschwitz, "o chicote se chamava der Dolmetscher, o intérprete, aquele que se fazia compreender por todos" (LEVI, 2004, p. 80), sua representação do traduzir e do tradutor indica a importância da tarefa como tarefa humana.

De fato, Levi constrói cenas de tradução em Auschwitz, onde traduzir se torna sobrevivência, desconcerto, ou até resistência. Em primeiro lugar, ao chegar ao Campo, os prisioneiros poliglotas assumem a tarefa de traduzir, para os companheiros desorientados, as primeiras informações sobre o lugar e as ordens das SS. No começo do capítulo "No fundo", os deportados, descem do caminhão após dias de viagem sem água e são fechados numa sala gelada, próximos a uma goteira de água não potável que desce de uma torneira. "Este é o inferno", deduz o narrador, visualizando um mundo infernal moderno naquela imagem de sala vazia onde, obrigados a ficar de pé, exaustos e sedentos, se insere uma nova consciência de tempo imóvel: "o tempo passa gota a gota" (LEVI, 1988 , p. 20). O primeiro evento que irrompe na imobilidade noturna é a busca por um tradutor, sem o qual as ordens dos alemães permaneceriam incompreensíveis:

Não estamos mortos: abre-se a porta, entra, fumando, um sargento SS. Olha-nos sem pressa; pergunta: - Wer kann Deutsch ?- Adianta-se um de nós que eu nunca vira, chamase Flesch ; será nosso intérprete. O SS fala longa e tranquilamente; o intérprete traduz. Devemos formar filas de cinco, deixando um espaço de dois metros entre um e outro; a seguir, despir-nos e fazer uma trouxa com nossas roupas conforme critério determinado [...] tirar os sapatos, com cuidado para que não nos sejam roubados (LEVI, 1988, p. 20). 
Uma série de perguntas forma-se entre os prisioneiros e o tradutor as reproduz, mas às vezes ele mesmo mostra perplexidade diante da crueldade nazista:

Estamos todos olhando para o intérprete, e o intérprete perguntou ao alemão, e o alemão fumava e o atravessou com o olhar de parte a parte, como se fosse transparente, como se ninguém tivesse falado.

Eu nunca tinha visto velhos nus. O Sr. Bergmann usava um cinto herniário, e perguntou ao intérprete se devia tirá-lo e o intérprete hesitou. O alemão compreendeu, porém, e falou sério ao intérprete indicando alguém; vimos o intérprete engolir seco, e em seguida disse: - $\mathrm{O}$ sargento manda o senhor tirar o cinto e receber o do $\mathrm{Sr}$ Coen. Viam-se as palavras amargas saindo da boca de Flesch, era o jeito do alemão rir (LEVI, 2012, p. 16, trad. nossa) ${ }^{2}$.

Sublinhamos o primeiro tempo presente que age em contraste com os restantes do passado. Para poder analisar esta citação, pre-

${ }^{2}$ Trata-se da mesma citação, cujo segundo trecho traduzimos novamente, pois a tradução da edição brasileira de 1988 tende a arrumar todo o texto, eliminando conjunções e mudando a pontuação e não segue os tempos verbais originais onde seria possível, escolhendo cancelar o contraste do início. Cfr. LEVI, 1988, p. 21. Em italiano: Tutti guardiamo l'interprete, e l'interprete interrogò il tedesco, e il tedesco fumava e lo guardò da parte a parte come se fosse stato trasparente, come se nessuno avesse parlato. Non avevo mai visto uomini anziani nudi. Il signor Bergmann portava il cinto ernario, e chiese all'interprete se doveva posarlo, e l'interprete esitò. Ma il tedesco comprese, e parlò seriamente all interprete indicando qualcuno; abbiamo visto l'interprete trangugiare, e poi ha detto: - Il maresciallo dice di deporre il cinto, e che le sarà dato quello del signor Coen -. Si vedevano le parole uscire amare dalla bocca di Flesch, quello era il modo di ridere del tedesco (Ibid., p. 16, sublinhado nosso). Ainda há o problema de dois tipos de passados (passato prossimo e passato remoto). O passato remoto (um passado, como o passé simple francês, utilizado para passados mais longínquos, em textos de histórias, fábulas, biografias etc.) substitui o presente e em seguida é atenuado pelo passato prossimo (como o passé composé, um passado mais próximo, mais usado: "abbiamo visto", "ha detto"). 
ferimos propor uma tradução que não mude o jogo dos tempos verbais com a intenção de garantir uma coerência sintática, pois o próprio escritor escolheu quebrá-la. E concordamos com Domenico Scarpa (1991, p. 236), segundo o qual entre os "milagres" que o escritor consegue obter, está o desmontar e o montar, sob o olhar do leitor, os tempos da narração.

Observe-se, então, a mudança de tempo verbal intercorrente entre o olhar em direção ao tradutor e a pergunta colocada por este ao SS. Mas o tradutor é transparente para o oficial nazista, porque pertence aos prisioneiros desumanizados. Não se trata do único exemplo de mudança de tempo verbal, embora aqui particularmente rápido. Mas o que acontece nesta defasagem gramatical? Como afirma Pier Vincenzo Mengaldo o presente atualiza a experiência e convida o leitor a adentrá-la, a sentir sua realidade incancelável, e por esta razão o tempo "desliza insensivelmente de histórico a acrônico, ou eterno" 3 . Ressaltaremos que o deslizamento acontece na mesma frase, desde o olhar do sujeito plural - o "nós" narrativo - enquanto observa o intérprete ("Estamos todos olhando para o intérprete"), isto é do presente de um gesto silencioso (o olhar), à ação do tradutor, na qual o verbo é transformado ou deformado ao passado ("o intérprete perguntou ao alemão"), alteração que permanece nas ações a seguir. O tradutor é, nesta frase, o motor da transformação, com sua fala se passa do presente ao passado, do mundo dos vivos ao mundo dos mortos, ele transfere os prisioneiros, como Caronte de uma margem à outra, e os leva até o olhar do alemão, que é (in)diferente, como se eles fossem de ar, almas perdidas sem corpos, pois ele olha "como se fosse transparente, como se ninguém tivesse falado."

Ao assumir o passado, o diálogo narrado entre o tradutor e o SS volta a ser testemunho, recordação. De repente o leitor, que estava dentro do Lager com o prisioneiro (por meio do presente usado no trecho anterior), retoma o lugar na plateia como espectador. Esta aproximação-distanciamento assemelha-se ao exercício de se colo-

${ }^{3}$ MENGALDO, 1997, p. 203-204. 
car no lugar de quem narra, entrar na narração ao máximo possível e conseguir ao mesmo tempo permanecer em parte fora, no lugar de quem deverá preservar sua capacidade analítica após ter vivido empaticamente o que leu.

Outro aspecto estilístico para a mudança temporal é identificável na utilização de elementos da narração oral $^{4}$, observado ainda por Mengaldo. Domenico Starnone (apud FERRERO, 2007, p. 49) utiliza uma expressão eficaz ao dizer que Levi está entre "os que escrevem deixando dentro da própria escrita um pouco de voz. Quem começa a ler, se sente mais ouvinte do que leitor." A liberdade da narração oral permite passagens temporais, enquanto presente e perfeito "distante" ou "histórico" (o "passato remoto") possuem ambos legitimidade para narrar fatos longínquos.

A nosso ver, no leitor pode-se instalar também a sensação de que o escritor esteja engajado numa tentativa en abîme para encontrar o enfoque certo - como o gesto de ajeitar o foco de uma lente fotográfica - para que, então, seja possível contar a ofensa. Como encontrar as palavras, pergunta-se Levi, quando o significado de "humanidade" é ofuscado, desfocado, embaçado, incerto? A transmissão é um contínuo reajuste expressivo, um terreno movediço de negociação entre experiência e narração.

Ainda podemos pensar em uma incoerência sintática, uma confusão gramatical como reflexo do desnorteamento, do estar de repente num mundo sem referências, sem hoje nem amanhã, sem as leis conhecidas da divisão temporal da vida comum.

O texto de Derrida sobre Blanchot, $L$ 'instant de ma mort, relato de um episódio de condenação a uma fuzilação suspensa no último instante, ajuda-nos a pensar sobre as mudanças temporais dos verbos

${ }^{4}$ Levi (2004, p. 148) comentou que seu primeiro livro "devia ser, mais do que um livro, um registro de gravador”. Todavia, Belpoliti (2015, p. 601) observa com razão que sua oralidade é sempre subordinada à escrita, ou pelo menos "não se trata da tipologia popular do narrador espontâneo, e sim a do narrador culto, de origem intelectual, um escritor que é antes de tudo um leitor (ou um ouvinte, como afirma em $A$ chave estrela)". De resto, é suficiente assistir a entrevistas em vídeo com Levi (disponíveis na Internet) para perceber o estilo de sua fala. 
em Levi. Derrida (1995, p. 51) analisa as expressões temporais e gramaticais capazes de captar e imobilizar o instante da não-morte narrado por Blanchot: "Não há um tempo só, e como um instante não possui nenhuma medida comum ao outro, a partir da causalidade introduzida pela morte, não é possível medir o tempo nem uma vez recuperada a percepção do real" ${ }^{5}$. Refletindo sobre as palavras de Derrida dedicadas a Blanchot, gostaríamos de sublinhar o quanto a presença da morte ordena ou desarruma o tempo, alienando o indivíduo da dimensão cronológica, que antes era um ponto de referência. No "buraco negro" de Auschwitz, podemos afirmar com Derrida (Ibid., p. 52) que o tempo não é mensurável; tanto é que passa "gota a gota" (LEVI, 1988, p. 20), quase parando, parado, ou é percebido como imóvel. E, neste sentido, o tempo do Lager apresenta-se como um extenso "instante" da própria morte. Até a alternância - possível no francês e no italiano - de tempos do pretérito de diferente qualidade (o passato prossimo e o passato remoto) parece estar a serviço da reviravolta da percepção temporal dentro do Campo e também da necessidade de transmitir o peso da ofensa.

$\mathrm{Na}$ cena seguinte as perguntas deparam-se com uma tradução impossível.

\begin{abstract}
Abre-se a porta, entra um alemão, é o sargento de antes; fala brevemente, o intérprete traduz : - O sargento mandou ficarem calados, isto não é uma escola rabínica. Vê-se que as palavras, estas palavras maldosas, que não são dele, fazem repuxar a sua boca, como se ele cuspisse um bocado nojento. Rogamos que pergunte o que estamos esperando, quanto tempo ainda vamos ficar aqui, que pergunte pelas nossas mulheres, que pergunte tudo, mas não, ele diz que não, que não quer fazer perguntas (LEVI, 1988, p. 22).
\end{abstract}

O tradutor, apesar de ser alemão, vivencia uma notável dificuldade, quando, ao usar aquele idioma - daquela forma e naquele

5 Trad.nossa. 
lugar -, vê-se obrigado a engolir o Lagerjargon com seus significados brutais e paradoxais; em suma, a violentar a linguagem.

Esse Flesch, que contra a sua vontade concorda em traduzir para o italiano frases alemãs geladas, e que se recusa a verter para o alemão as nossas perguntas, porque sabe que não adianta, é um judeu alemão de uns cinquenta anos [...] É um homem retraído e caladão, pelo qual sinto um espontâneo respeito, porque compreendo que começou a sofrer antes de nós (Ibid., p. 22-3).

Aqui, o tempo presente acompanha a sequência inteira, mais subjetiva, onde prevalecem o pensamento do momento e o estado de ânimo do narrador.

O tradutor Flesch, em seu papel improvisado, mas fundamental, encontra-se na impossibilidade de reproduzir as perguntas dos prisioneiros, e o narrador reconhece o drama de sua condição. Percebemos um elo com o conhecido episódio em que Primo arranca um pedaço de gelo para satisfazer a sede "feroz", e um Kapò intervém brutalmente: "Warum?" (Por que?) pergunta o prisioneiro, e a seca resposta é: "Hier ist kein warum" (aqui não existe por quê). Qualquer ponto de interrogação é abolido em função de frases imperativas, exclamativas, unilaterais destinadas a dar ordens sobre vida e morte. E onde o diálogo desagrega-se, a tradução também é amputada. O percurso será o inverso no capítulo "O canto de Ulisses", quando, a partir de uma tradução falha, mas expressiva, Levi conseguirá estabelecer uma daquelas frestas por onde passam a poesia, a comunicação humana, o pensamento vivo.

\section{3. Ética de uma comunidade testemunhal}

A atividade tradutória no Campo, portanto, abrange também as esferas da poesia. Levi, como Jorge Semprún e Ruth Klüger, 
atribui o valor de suporte aos poemas e à potência simbólica da literatura, em contextos extremos. No capítulo "O canto de Ulisses" o prisioneiro caminha, num breve momento de pausa, ao lado de um companheiro francês interessado na língua italiana; logo, lhe vem à mente um trecho da Comédia de Dante, tenta lembrar as rimas exatas, traduzir os versos, ilustrar interpretações ao amigo, tomando o cuidado necessário para não serem descobertos. O texto ausente, mas memorizado na escola, fundador da língua italiana, permite ressignificar tanto a linguagem poética quanto a língua-mãe de Levi, naquele momento língua-pátria ou, melhor, língua-mátria. Os versos apresentam-se na memória do prisioneiro como voz de um antepassado, uma raiz, um guia, enquanto seu amigo Jean, apelidado (por Levi) de Pikolo, escuta concentrado. Através da tradução oral para o francês, mesmo se lacunosa, o prisioneiro reedita clandestinamente o XXVI canto, o canto da viagem de Ulisses em mar aberto além de Gibraltar e da sede humana de conhecimento. A centralidade deste ouvinte leva Robert Gordon (2003, pp. 216-217) a afirmar que, no episódio, "o verdadeiro herói não é Dante, não é Ulisses e nem é Levi, mas, sim, Jean Pikolo", "um mestre da humana arte de escutar." O diálogo entre os dois prisioneiros, no qual Levi concentra todas as energias na tradução do canto da Comédia, é visto por Gordon, como “a cena primária da ética da escuta de Levi” e também o antípoda do pesadelo do sobrevivente de não ser escutado - aquele sonho no qual, ao voltar à sua casa, ninguém entre os familiares presta atenção à narração sobre o Campo ${ }^{6}$.

6 “Aqui está minha irmã, e algum amigo (qual?), e muitas outras pessoas. Todos me escutam, enquanto conto do apito em três notas, da cama dura [...]. Conto também a história da nossa fome, e do controle dos piolhos, e do Kapo que me deu um soco no nariz [...]. É uma felicidade interna, física, inefável, estar em minha casa, entre pessoas amigas, e ter tanta coisa para contar, mas bem me apercebo que eles não me escutam. Parecem indiferentes; falam entre si de outras coisas, como se eu não estivesse. Minha irmã olha para mim, levanta, vai embora em silêncio. Nasce, então, dentro de mim, uma pena desolada, como certas mágoas da infância" (LEVI, 1988, p. 60). 
Lina Insana (2009, p. 48) identifica no episódio citado o início de uma "post-Auschwitz audience", cujo iniciador seria a personagem de Pikolo. A afirmação da estudiosa chama a atenção sobre uma ação em conjunto: "He doesn't merely teach Jean the passage; they create a translation of it together, in community" (Ibidem). Esta comunidade de tradução é metáfora da comunidade das testemunhas. Podemos acrescentar que Levi (2012, p. 99) constrói narrativamente seu modelo de testemunha, nas reações referidas a Pikolo: "muito atento", "bom" "me pede para repetir", "percebeu que lhe concerne" "recebeu a mensagem", "concerne a nós dois". Essas são as atitudes do ouvinte, enquanto o narrador tentava lembrar, traduzir e explicar os versos de Dante, testemunha ficcional do testemunho de Ulisses sobre o próprio naufrágio.

Uma cena de $A$ trégua (1963) configura-se como oposta, apresentando uma não tradução, ou uma omissão de tradução: após a chegada dos soviéticos e já fora do Campo, um advogado se oferece para traduzir o relato que o ex prisioneiro tenta fazer a um pequeno público de poloneses. Quando o narrador percebe que não está sendo traduzido com precisão e que o gentil advogado está mudando a história evitando a palavra "judeu", o sentimento de desamparo, frustração, desilusão pela voz abafada é visto como realização do pesadelo recorrente contado em Se questo è un uomo, aquele pesadelo de voltar e não ser ouvido.

Percebi que a onda quente do sentir-se livre, do sentir-se homem entre os homens, do sentir-se vivo, refluía longe de mim. Encontrei-me de pronto velho, exangue, cansado além de toda medida humana: a guerra não terminara, guerra é sempre. Os meus ouvintes foram-se em pequenos grupos: deviam ter entendido. Eu sonhara algo semelhante, todos sonháramos, nas noites de Auschwitz: falar e não sermos ouvidos, de reencontrar a liberdade e permanecer solitários (LEVI, 1997, p. 51). 
O que nos interessa é a descrição da decepção diante de uma tradução desviada, que impede a transmissão da experiência e nega ao sobrevivente a escuta, amplificando a tentativa de cancelamento do testemunho e, portanto, a presença ou ausência da citada witness audience. Se este círculo testemunhal inclui o ouvinte, ele é convocado para que assuma uma responsabilidade no testemunho, como afirma Jeanne Marie Gagnebin:

\begin{abstract}
Testemunha também seria aquele que não vai embora, que consegue ouvir a narração insuportável do outro e que aceita que suas palavras levem adiante, como num revezamento, a história do outro: não por culpabilidade ou por compaixão, mas porque somente a transmissão simbólica, assumida apesar e por causa do sofrimento indizível, somente essa retomada reflexiva do passado pode nos ajudar a não repeti-lo infinitamente, mas a ousar esboçar uma outra história, a inventar o presente (GAGNEBIN, 2006, p. 57).
\end{abstract}

Se a escuta faz parte do testemunho, quem escuta também é uma testemunha e o torna possível. O mesmo acontecerá com o leitor e, a partir disso, podemos estender a tarefa a quem traduz. É aqui que surge uma ética tradutória: a literatura de testemunho nos pede com força a assunção de uma responsabilidade na escuta, e o tradutor, por ser um leitor-ouvinte profundo, precisa assumir um posicionamento claro relativamente às questões do testemunho, pois ele, exatamente como o escritor, encontra-se no embate entre urgência de testemunhar e a procura da forma pertinente.

Acreditamos que não escutar seja particularmente problemático no caso da literatura de testemunho, levando em consideração que escritores como Primo Levi, Germaine Tillion, Robert Antelme, Elie Wiesel, Robert Antelme, empenharam-se pela transmissibilidade da experiência e principalmente pela escuta de sua narrativa testemunhal desde logo. Muitos sobreviventes preferiram calar e tentar esquecer, alguns escritores resolveram testemunhar somente mais tarde (como, por exemplo, Jorge Semprun, Imre Kertész, 
Aharon Appelfeld, Ruth Klüger). De qualquer forma a literatura tematiza e problematiza com muita frequência a questão do silêncio versus testemunho/narração e, ao mesmo tempo, desvela o dilema insolúvel da condição aporética do sobrevivente, sintetizada por Elie Wiesel na conclusão: "Calar é proibido, falar é difícil, se não impossível” (Wiesel, 2013, p. 13). A literatura, no entanto, consegue representar um espaço onde incluir possibilidades e impossibilidades da linguagem. Deste espaço faz parte um leitor que, como vimos, se supõe ouvinte de um testemunho.

\section{Marcas de uma relação}

E aqui torna-se necessário abordar a aventura das traduções deste livro fundamental que é Se questo è un uomo. A atitude de Levi diante da tradução em alemão nos diz muito sobre a necessidade da testemunha de se sentir escutada e compreendida e do escritor de ser lido de maneira profunda. O escritor debateu as sutilezas do estilo com seu tradutor alemão, dando importância a uma série de aspectos que em muitas outras traduções são negligenciados: o jargão do Lager, o plurilinguismo, questões semânticas e intertextuais, jogo dos tempos verbais ${ }^{7}$.

Quando, em 1961, Heinz Riedt traduziu Se questo è un uomo para o alemão, a questão da "acústica" permanecia central com uma motivação clara:

queria que naquele livro, especialmente em sua versão alemã, não se perdesse nada das asperezas, das violências feitas à linguagem que, de resto, me esforçara ao máximo para reproduzir no original italiano. (LEVI, 2007, p. 142)

\footnotetext{
7 Parte das cartas entre Levi e o tradutor Heinz Riedt estão arquivadas como Letters Primo Levi-Heinz Riedt. Ian Thomson collection, fasc.1406/2/22, Wiener Library, London.

${ }^{8}$ Trad. nossa. Discordamos da tradução brasileira que opta por "violência imprimida na linguagem" (LEVI, 2004, p.149), diferente de "violências feitas à
} 
A finalidade era restituir um alemão "que soasse ao ouvido deles como uma língua estrangeira", um estranhamento ao ouvir o jargão do campo, a língua nazificada analisada também pelo filólogo Victor Klemperer. Traduzir Se questo è un uomo em alemão significava "devolver a acústica de Auschwitz a seu lugar de origem” (SCARPA, 2015, p. 65). O leitor alemão havia de vivenciar a dissonância, o estranhamento sonoro de sua língua usada para a morte, a ferida aberta da história recente, e esta sonoridade o lembraria de uma ameaça permanente (Ibidem).

A intuição de Levi, como diz Domenico Scarpa, foi a de colocar os alemães na frente de um "espelho acústico" (Ibidem) que levaria a perceber a correspondência entre o alemão degradado de Ist das ein Mensch? e o contexto propício ao ódio antissemita.

Levi atribuía suma importância à tradução alemã em prol da prioridade de se comunicar com os alemães, primeiros destinatários do livro, por uma necessidade de compreensão e ressarcimento moral ao mesmo tempo:

O encontro que eu esperava, e com o qual tão intensamente sonhava (em alemão) à noite, era um encontro com um daqueles de lá, que dispuseram de nós, que não nos olharam nos olhos, como se nós não tivéssemos olhos. (LEVI, 1994, pp. 214-215)

Durante o trabalho do tradutor alemão, Levi pediu-lhe que não mudasse sequer uma palavra e que lhe submetesse as páginas, à medida que eram traduzidas:

eu intimava-o a não cortar ou trocar uma só palavra do texto, e exigia mandar-me o original da tradução por partes, capítulo por capítulo, à medida que o trabalho prosseguisse;

linguagem", enquanto no original lemos: "quelle violenze fatte al linguaggio" (LEVI, 2007, p.142). 
queria controlar sua fidelidade, não só lexical, mas interna" (Ibid., p. 145).

Partindo do desejo explícito de ter os alemães como público-alvo, podemos deduzir, portanto, um aspecto tradutório de seu primeiro livro, paradoxal, mas interessante: Levi o escreve como uma tradução não apenas da experiência, mas da linguagem-atmosfera do campo e quer que seja traduzido para o alemão, como se o alemão fosse um segundo original, seu duplo:

De um certo modo, não se tratava de uma tradução, mas, antes, de uma restauração: esta versão era, ou eu queria que fosse, uma restitutio in pristinum, uma retroversão para a língua na qual as coisas tinham ocorrido e às quais se referiam" (Ibid., p. 148).

De fato, Levi fala da edição alemã como se fosse a continuação do mesmo texto: "Como compreenderá, é o único livro que escrevi, e agora que acabamos de vertê-lo para o alemão, sinto-me como um pai cujo filho chegou à maioridade e vai embora, e dele não se pode mais ocupar" (Ibidem). O verbo italiano trapiantare (traduzido com o menos metafórico "verter") aponta para um transplante num outro terreno da mesma criação-criatura, e o fato de que a tradução alemã seja comparada a um filho mais velho e maior de idade prova o quanto esta etapa marcaria a ultimação da escrita de Se questo è un uomo, sua realização plena. Como sugere Henri Meschonnic (1999, p. 31), quando fala da necessidade de escuta: "traduire peut continuer le texte". Em suma, estamos diante de um texto prolongado, ampliado, que compõe com seu original quase uma unidade. Não seria assim para todo texto traduzido?

Evitando o conflito entre posições sobre tradução que atribuem a primazia absoluta ao texto original ou à criação do tradutor, a concepção de uma nova obra composta tanto do texto traduzido que de sua tradução nos levaria fora do impasse (como 
muitas edições poéticas de fato concretizam, ao colocar as duas versões, lado a lado).

Partimos da premissa de que a tradução de um texto de literatura testemunhal requer uma dupla clareza, em relação à tradução da literatura e em relação à voz-estilo encontrada pela testemunha. A relação testemunho-tradução ajuda, portanto, a ressaltar um problema maior, de relações entre um texto e a escuta que o tradutor aciona. Não poderia o tradutor, de qualquer obra literária, ser considerado a testemunha de algo? De um texto, de um estilo, de uma tentativa de transmissão, de representação? E aqui valeria a pena lembrar a proposta de Meschonnic (1999, p. 103): considerar a tradução como relação entre textos e não entre línguas. E a relação é um unicum, resultado da alquimia de dois elementos em diálogo. Ampliando a ideia de Insana da testemunha como tradutor gostaríamos de acrescentar a inversão: o tradutor como testemunha. Testemunha de um acontecimento chamado "texto" ou, melhor, de uma relação entre textos. A responsabilidade ética que desponta da tarefa do tradutor de literatura testemunhal pode reforçar caminhos da tradução de toda literatura.

\section{Referências}

ALIGHIERI, Dante. A divina comédia. Inferno. Trad. Ítalo Eugênio Mauro. S. Paulo: Editora 34, 1999.

ANTELME, Robert. L'espèce humaine. Paris: Gallimard, 2010.

DERRIDA, Jacques. L’'istante della mia morte. Aut-aut, [S.L] n. 267-8, 1995.

FERRERO, Ernesto. Primo Levi, la vita, le opere. Torino: Einaudi, 2007. 
GAGNEBIN, Jeanne Marie. Lembrar, escrever, esquecer. São Paulo: Editora 34, 2006.

GORDON, Robert S.C. Primo Levi: le virtù dell’uomo normale. Roma: Carocci, 2003.

INSANA, Lina N. Ardous tasks. Primo Levi, translation and the transmission of holocaust testimony. Toronto: University of Toronto Press Incorporated, 2009.

LEVI, Primo. Se questo è un uomo (Notas de Alberto Cavaglion).Torino: Einaudi, 2012.

. É isto um homem?.Trad . Luigi Del Re. Rio de Janeiro: Rocco, 1988.

1997.

. A trégua . Trad. Marco Lucchesi. São Paulo: Companhia das Letras,

. Tutti i racconti. Torino: Einaudi, 2005.

. 71 contos de Primo Levi. Trad. Maurício Santana Dias. São Paulo: $\bar{C}$ Companhia das Letras, 2005.

- Letters Primo Levi-Heinz Riedt. Ian Thomson collection, fasc. $\overline{1406 / 2 / 22}$, Wiener Library, London.

MENGALDO, Pier Vincenzo. Lingua e scrittura in Levi. In: FERRERO, Ernesto (Org.). Primo Levi: un`antologia della critica. Torino: Einaudi, 1997, pp. 169-242.

. La vendetta è il racconto. Torino: Bollati Boringhieri, 2007.

MESCHONNIC, Henri. Poétique du traduire. Paris, Verdier, 1999.

SCARPA, Domenico. Leggere in italiano, ricopiare in inglese. In: GOLDSTEIN, Ann; SCARPA, Domenico. In un 'altra lingua. (Lezione Primo Levi). Torino: Einaudi, 2015. 
. Chiaro/scuro. In: BELPOLITI, Marco (Org). Primo Levi. Riga, n.13. Milano: Marcos y Marcos, 1991.

SEMPRUN, Jorge. Le grand voyage. Paris: Folio, 1990.

. L'écriture ou la vie. Paris: Gallimard, 1994.

WIESEL, Elie. Prefáce. In: . La nuit. Paris: Les éditions de minuit, 2007.

. A noite. Tradução de Irene Ernest Dias. Rio de Janeiro: Ediouro, 2001.

Recebido em: 25/03/2018

Aceito em: 27/07/2018

Publicado em setembro de 2018

Anna Basevi. E-mail: annabasevi@hotmail.com

ORCID: https://orcid.org/0000-0002-6635-1239 